\section{SURGICAL TREATMENT OF PULMONARY TUBERCULOSIS.}

\section{BY}

BERNARD HUDSON, M.D., M.R.C.P., SWISS FEDERAL DIPLOMA,

MEDICAL SUPERINTENDENT, VICTORIA SANATORIUM, DAVOS-PLATZ. (With special 1'late.)

The two following cases illustrate the value of surgical treatment in pulmonary tuberculosis which has failed to respond to treatment by general methods.

\section{CASE I.}

A man, aged 33, was admitted in October, 1927, suffering from very extensive disease in the left lung. The patient obviously had long-standing disease, and had been in bed already for nearly a year- before admission here. He was very ill, thin, with a considerable amount of sputum and cough, and thoroughly toxaemic. $\boldsymbol{I}$-ray examination showed the left lung to be practically opaque, although signs of cavitation could just be detected in the upper lobe. The temperature range was very consistent, always about $100^{\circ}$ to $101 \mathrm{~F}$. each evening. Artificial pneumothorax had been attempted in England, but had failed owing to the presence of strong adhesions. It was attempted again here by me, with the same result. The condition of the right lung, although the apex was slightly affected, was very good. As the patient was obviously going downhill, a consultation was called with a view to the advisability of surgical intervention. A plastic operation was decided upon, and on November 4th an extrapleural thoraco-
plasty was performed in one sitting, under local anaesthesia, parts of every rib being removed.

The patient stood this very severe operation remarkably well, and six weeks after was able to get up and lead a quiet, ordinary life, for the first time for over a year. His condition after four months (March, 1928) was extremely good; he had gained two kilos in weight, and the sputum had almost ceased, what there was being tubercle negative. The temperature range was never higher than $99.2^{\circ} \mathrm{F}$. (rectal) at night, and all symptoms of activity had disappeared. The patient returned to England, for urgent reasons, during the summer, and followed his profession (solicitor) in London without any ill effects at all. He returned to Davos $M$ November, 1928, for the winter. His condition is now excellent: he weighs 86 kilograms, as against 73 a year ago. He has steadily improved since the operation.

Case Ir.

A man, aged 24, was admitted in January, 1927, suffering from very widespread and active tuberculosis of the left lung, the upper lobe of the right lung being also slightly affected. The family disease settled down to a certain extent, but was never really quiescent, and it became quite obvious that it was slowly spreadquiescent, and it became quite obvious that it was slowly spreading, and undermining the patient's constitution. An artificial
pneumothorax was proposed six month previously, but the patient pneumothorax was proposed six month previously, but the patient
refused it, being desirous of trying the sanocrysin treatment. He refused it, being desirous of trying the sanocrysin treatment. He other. At length, in October, 1927, he consented to have an artificial pneumothorax attempted. The induction was a complete success. However, on radiographic examination after the first few fillings, it was seen that the collapse, although complete over the greater part of the lung, and at the base, was hindered at the apex by what appeared to be a strong fibrous adhesion, which was holding open a latge lateral cavity. It was evident which was holding open a large lateral cavity. It was evident that this would not give way except by cauterization, and accord-
ingly this was aitempted on January $91 \mathrm{~h}, 1928$. On examination ingly this was aitempted on January $91 h, 1928$. On examination
by the thoracoscope, it was seen that there were actually two large adhesions, one behind the other, each containing numerous small blood vessels. Two or three other thinner adhesions were also present.

The largest adhesion was firsi dealt with. A trocar was introduced by the side of the thoracoscope, and in order to obviate bleeding - a troublesome and most dangerous complication-a third bleeding - a troublesome and most dangerous complication-a third
of the largest adhesion was first coagulated by the diathermic of the largest adhesion was first coagulated by the diathermic
cautery, and subsequentiy divided by the electric thermo-cautery. cautery, and subsequentiy divided by the electric thermo-cautery.
This procedure was continued tor the middle third of the adhesion, This procedure was continued for the middle third of the adhesion, completely divided without a single drop of blood escaping. At the same sitting a portion of the second big adhesion was treated in the same way, but; the operation having lasted about three hours, it was decided to complete the procedure at a later date. There was no yeaction to speak of. Fillings were given twice weekly in order to provide as much room as possible and to stretch the adhesion, which was a very short and thick one. This and some smaller ones were dealt with a month later, in the same way as previously described, and complete collapse of the lung ensued.

The patient has never looked back, and he has had no conplications (fluid, etc.) whatever. He has a filling every month, is in excellent general condition, and has gained many pounds in weight. He has no fever, and no cough or expectoration. I last induction of the artificial pneumothorax, but before the cauteriza-

' tion. It shows well the holding open of the cavity by adhesions. Fig. 2 shows the condition after the cauterization.

In the first case the ordinary treatment by rest in bed and climatic conditions proved useless, and artificial pneumothorax was impossible owing to the presence of massive adhesions. In the second case although artificial pneumothorax was performed successfully as regards the greater part of the lung, it was really unsuccessinl because of the apical adhesions which held open the large cavity in the upper lobe. This partial collapse of the upper lohe was not only a hindrance to the patient's cure, but was a positive clanger, owing to the presence of the widely open thinwalled carity. In this case the operation of dividing the adhesions was extremely interesting owing to their great thickness and rascularity. The diathermic cantery was used with marked success, there being no bleeding either during the operation or subsequently.

I am indebted to Mr. P. G. Sutton, M.S.R., of the I-Ray Institute, Davos-Platz, for the radiographs.

\section{Atemoranda:}

\section{MEDICAL, SURGICAL, OBSTETRICAL.}

\section{A NORMAL VENTRICULOGRAM. \\ (With special Plate.)}

The case here described may be of some interest from the point of view of showing the normal appearance of the lateral rcnticles, and the relationship of the third ventricle to the foregoing in a case of ventriculography.

The patient was a man in early middle life, who was admitted to the Maida Vale Hospital for Epilepsy and Paralysis complaining of headache and convulsions. On-admission he was found to have nystagmus of the pupils, but the dises were clear. Examination of the central nervous system revealed the presence of deafness of the central nervous system revealed the presence of deafness
in the left car, suggesting involvement of the eighth nerve. The tongue was protruded to the left, implicating the twelfth crania nerve. The Wassermann reaction was negative in both the blood and the cerebro-spinal fluid.

Ventriculography, or the injection of air into the ventrickes, was performed under local anaesthesia in the hope that a diagnosis might be obtained as regards the presence or absence of a cerebral tumour. Skiagrams were accordingly taken showing the ventricles anteriorly, posteriorly, and laterally. The anterior and posterior rentricles are alone referied to in this article.

In the anterior vien of the ventricles the two anterior horns of the lateral ventricle are clearly seen. They are filled with air, and are closely approximated, with the third rentricle lying below. In the middle line the pineal body can be seen through the third ventricle.

In the posterior view of the rentricles it will be observed that the third rentricle has emptied itself into the lateral rentricles, and only the posterior horns of the lateral ventricles are seen; these are normally situated. The pineal body can be made out to be in the middle line.

I desire to thank Dr. W. Russell Brain for permission to use the clinical notes.

H., Martix Grey, M.R.C.S., L.R.C.P., Paralysis.

RAPID RECOVERY FROM PLEURO-PNEUMONIA. THE arrest of lobar pneumonia with pleurisy within thirty hours of its onset seems to be a gratifying achiercment and worthy of record.

I was recently called to see a man, aged 55, whom I had attended four years previously with double pneumonia and pleurisy; from this he nearly died, but eventually made a good recovery. On November 1st, 1928, he went for a motor drive in the country and fell asleep on the ground with his coat off. He retired to bed that night feeling perfectly well, but, after a few hours' sleep, he awoke and was very restless. A little later he had a rigor and vomited, and immediately complained of shortness bf breath, with a stabbing pain over the lower part of the left side of the chest, laterally and in front. A similar pain was felt over of the chest, laterally and in front. A temperature was $101.4^{\circ} \mathrm{F}$. the tip of the left shoulder, and his tempespirations were short I saw him at 9.30 that morning, when his respirations were shorl, quick, and painful. He coughed then for the first time and sight of which confirmed his impression that another attack of preumonia was beginning. Examination revealed signs of consoli preumon the left base, diminished vocal fremitus, an impaired dite up to the angle of the scapula, diminished air entry, and distant voice sounds; a fine plcuritic rub was heard over this arta and extending to the froni.

He was ordered hot linseed poultices every two hours, the first of which contained mustard, and cachets four-hourly, containing half a gram each of aspirin and diuzetin, and 0.12 gram of quinine. The temperature and pulsc rate remained ronstant all 


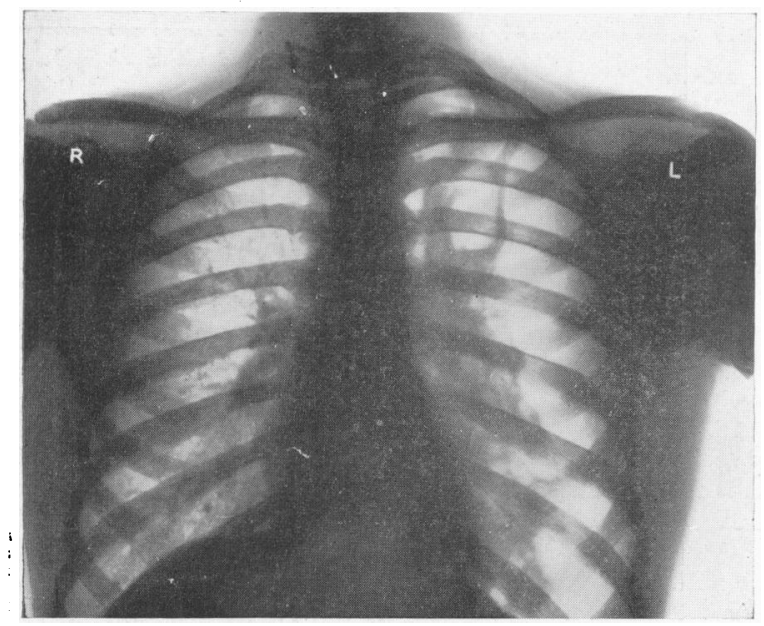

FIG.1.-Case II : Radiogram showing condition before cauterization.

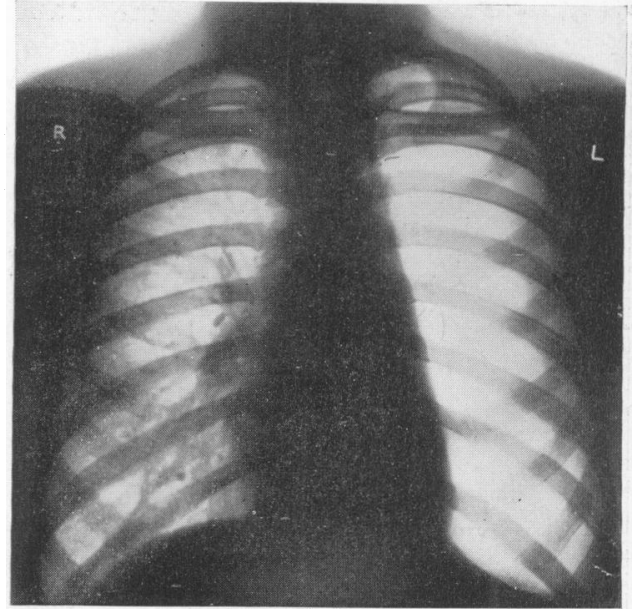

FIG. 2.-Case II : Condition after cauterization.

H. MARTIN GREY: A NORMAL VENTRICULOGRAI.

(See page 15.)

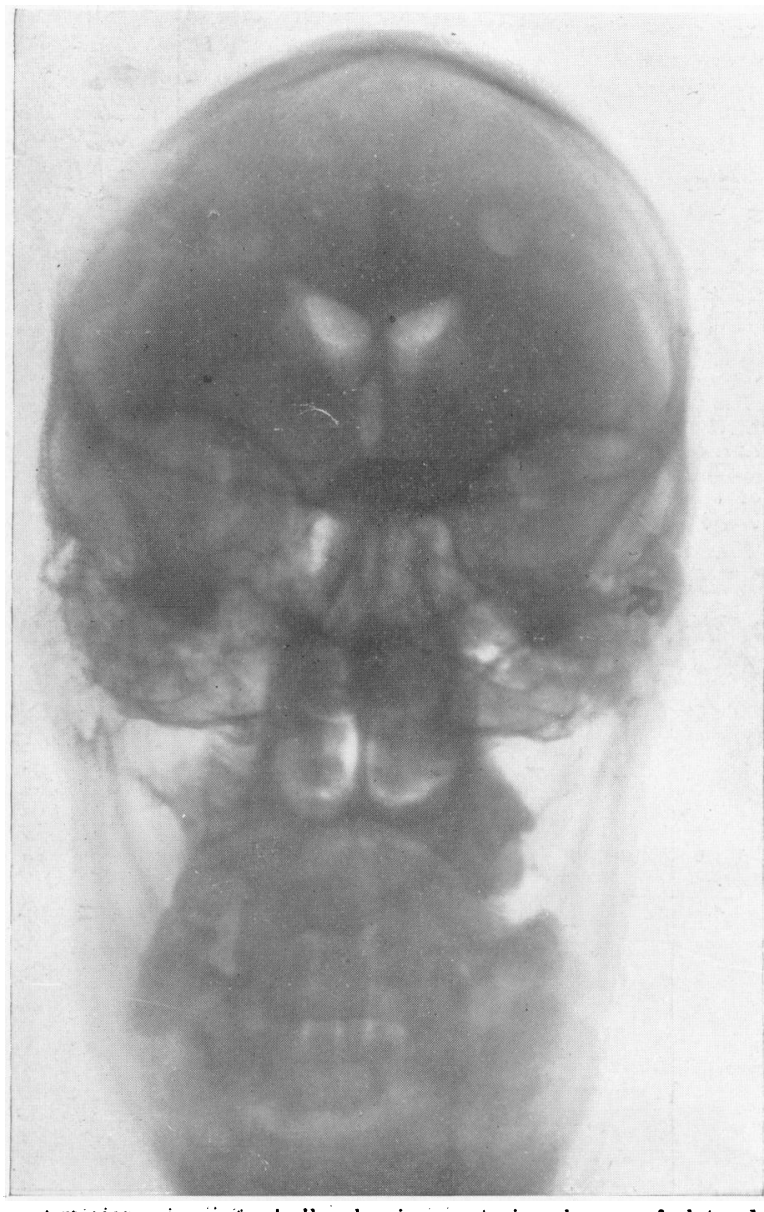

'osterior view of skull, showing anterior horns of lateral ventricles close together, with the third ventricle lying immediately

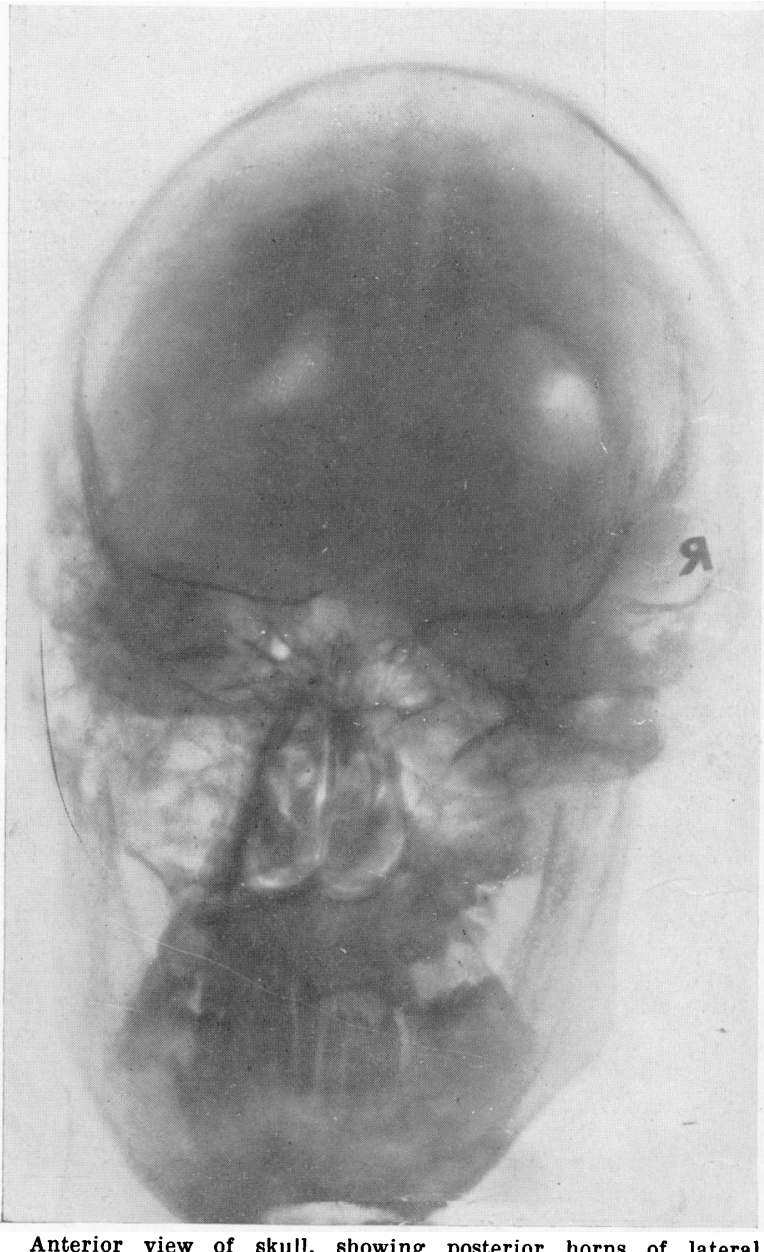

Anterior view of skull, showing posterior horns of lateral ventricles widely separated. 